\title{
Effects of egg weight and in ovo injection of $\alpha$-tocopherol on chick development, hatching performance, and lipid-soluble antioxidant concentrations in quail chick tissues
}

\author{
Elif Babacanoğlu, Mehmet Reşit Karageçili, and Filiz Karadaş \\ Department of Animal Science, Faculty of Agriculture, Van Yüzüncü Yıl University, \\ Van, 65080, Turkey \\ Correspondence: Elif Babacanoğlu (elifbabacanoglu@yyu.edu.tr)
}

Received: 10 January 2018 - Revised: 14 March 2018 - Accepted: 21 March 2018 - Published: 20 April 2018

\begin{abstract}
Lipid-soluble antioxidants can be more effective for chick development when provided via in ovo (IO) injection than when supplemented to the maternal diet. This study was conducted to evaluate the effects of egg weight (EW) and IO injection of $\alpha$-tocopherol on chick development, hatching performance and lipid-soluble antioxidant concentrations in residual yolk sac (RYS), liver and brain tissues of quail chicks. Eggs were obtained from quail breeders at days 72 and 128 of age and incubated at $37.8^{\circ} \mathrm{C}$ and $60 \%$ relative humidity. Each egg was numbered and weighed prior to incubation, and the average EW of all eggs was $11.76 \pm 0.05 \mathrm{~g}$. The eggs were divided into light $(<11.76 \mathrm{EW}$; EWL) and heavy $(>11.76 \mathrm{EW}$; EWH) groups (148 eggs per EW). Each EW group was divided into two IO groups: the control (non-injection) group and $\alpha$-tocopherol group, in which $3.75 \mathrm{mg}$ of $\alpha$-tocopherol per egg was injected into the yolk sac followed by a $120 \mathrm{~h}$ incubation period. There were 64 eggs for each EW-IO treatment combination (16 eggs per EW per tray). The chick and RYS weights were significantly lower in the EWL group than in the EWH group. A significant EW by IO interaction suggested that IO increased the eggshell temperature of light quail eggs. The non-injected light eggs had a shorter hatching time due to the interaction of EW with IO. Hatchability, embryonic mortalities, and the cumulative hatching rate were not affected by EW or IO. The chick and middle toe lengths increased following IO administration $(P<0.05)$, which indicated that IO administration had positive effects on chick quality. However, shank length decreased following IO administration with an unchanged relative asymmetry (RA). IO significantly affected the absolute weights of the liver and heart and the relative weight of the heart, which was lower in the $\alpha$-tocopherol group than in the control group. IO administration had no effect on total retinol and carotenoid concentrations in the RYS, liver and brain. Vitamin E, $\alpha$-tocopherol and $\delta$-tocopherol concentrations in the RYS, liver and brain were significantly higher in the $\alpha$-tocopherol-treated chicks than in the control chicks. The highest brain $\alpha$-tocopherol concentration was found in the $\alpha$-tocopherol-treated chicks of the EWH group, indicating a significant interaction between EW and IO. The highest total lipid-soluble antioxidant concentrations were obtained following IO $\alpha$-tocopherol treatment $(P<0.05)$, in the order brain $<$ liver $<$ RYS, but this pattern was not observed with $\delta$ tocopherol. In conclusion, IO injection of $\alpha$-tocopherol into the yolk sac affected the concentrations of tissuespecific lipid-soluble antioxidants in the RYS and tissues of newly hatched quail chicks, and EW had effects on various parameters.
\end{abstract}




\section{Introduction}

Hatching performance and chick weight may be influenced by the process of egg formation, which is affected by various factors such as egg weight (EW), egg quality, yolk nutrients, yolk antioxidant concentrations and variations in embryonic development (Surai et al., 2016). Eggs of different weights have different physical and chemical characteristics that affect embryo development depending on the concentrations of proteins, lipids, vitamins and antioxidants in the egg yolk (Burley and Vadehra, 1989).

Antioxidants are responsible for maintaining antioxidative protection in the tissues during embryonic development (Surai, 1999). Lipid-soluble antioxidants, such as vitamins $\mathrm{A}$ and $\mathrm{E}$ and carotenoids, are predominantly transferred to the developing embryonic tissues from the yolk sac during incubation (Surai et al., 1996; Surai, 1999). The yolk and the yolk sac membrane (YSM) contain high concentrations of vitamin A (Gaál et al., 1995), vitamin E, and carotenoids (Surai et al., 1996). The accumulation of vitamins A and E and carotenoids corresponds to extensive liver metabolism and decreases free radical formation (Surai et al., 1996). In the living organism, all antioxidants operate in cooperation with each other to form an integrated antioxidant system. The cooperative interaction of antioxidants in the embryonic cells is vital for the maximum protection of the embryo from the detrimental effects of free radicals (Surai, 2002). Oxidised vitamin $\mathrm{E}$ can be converted back into the active form by reacting with other antioxidants (Bohm et al., 1997). However, the effect, concentration and metabolism of these lipidsoluble antioxidants are dependent on dose, age (Khan et al., 2012), tissue and species (Surai, 2002; Karadas et al., 2011).

Vitamin $\mathrm{E}$ is the major player in antioxidant defence at the cellular and subcellular levels (Surai et al., 2016) and is known to be the most effective natural lipid-soluble and chain-breaking antioxidant. Structural analyses of vitamin E have revealed that there are four tocopherol molecules $(\alpha$, $\beta, \gamma$ and $\delta$ ) and four tocotrienols $(\alpha, \beta, \gamma$ and $\delta$ ) with antioxidant activity. Surai et al. (1996) reported that more than $80 \%$ of vitamin $\mathrm{E}$ in embryonic tissues is represented by the most active form, $\alpha$-tocopherol. Other isomers of vita$\min \mathrm{E}$ are found in the egg yolk and embryonic tissues, but at much lower concentrations. Furthermore, $\alpha$-tocopherol exhibits its highest biological activity during the development of the embryo (Surai et al., 2016). Ionov et al. (1994) reported that the concentration of $\alpha$-tocopherol in the egg yolk of quail was $252.4 \mu \mathrm{g} \mathrm{g}^{-1}$. The $\alpha$-tocopherol level in the yolk sac increases by $3-5$ times during the last week of incubation (Surai, 2002). Vitamin E is absorbed from the residual yolk sac (RYS) by the YSM and is then transferred to the liver during the prenatal development period of the avian embryo. The liver is the major site of vitamin $\mathrm{E}$ accumulation in the avian embryo. Thus, vitamin $\mathrm{E}$ accumulation in the liver during embryonic development is considered an adaptive mechanism in response to stress conditions during the hatching process (Surai, 2002). The chick embryonic brain is characterised by levels of vitamin $\mathrm{E}$ that are approximately 100 -fold lower than those in the liver (Surai et al., 1996), and this apparent deficiency in the brain's antioxidant defence capacity is further compounded by the relatively low levels of vitamin A and carotenoids (Speake et al., 1999). In this study, tissues were selected according to their roles in lipid assimilation (liver), their polyunsaturated fatty acid (PUFA) content (brain) and their storage deposits (RYS) at hatching.

Vitamin $\mathrm{E}$ in the maternal diet can have profound effects on the health status, growth and development of the newly hatched chick. However, Hossain et al. (1998) observed that in ovo (IO) injection of vitamin $\mathrm{E}$ was more efficient in increasing the immune response of chicks than vitamin $E$ supplementation to the maternal diet. Therefore, the aim of this study was to evaluate the effects of EW and IO $\alpha$-tocopherol on eggshell temperature during incubation, hatching performance, chick development and lipid-soluble antioxidant concentrations in quail chick tissues at hatching.

\section{Material and methods}

This study was approved by the Van Yüzüncü Yil Üniversitesi Animal Use and Care Committee (permit number 2017-01).

\subsection{Animal materials and experimental design}

Hatching eggs were obtained from a commercial farm of Japanese quail (Coturnix coturnix japonica) at days 72 and 128 of age in their first year of laying. Quail breeders were fed the same diet and reared under similar environmental conditions. The eggs were stored for 7 days at $15^{\circ} \mathrm{C}$ and $75 \%$ relative humidity. A total of 296 hatching eggs used in the experiment were divided into two egg weight (EW) groups as 148 eggs per EW group: a light group $(<11.76 \mathrm{EW}$, EWL) and a heavy group (>11.76EW, EWH). Each egg was numbered and weighed prior to incubation. The average EW was $11.76 \pm 0.05 \mathrm{~g}$. The average EWs of the EWL and EWH groups were $10.84 \pm 0.05 \mathrm{~g}$ (between 8.21 and $11.75 \mathrm{~g}$ ) and $12.58 \pm 0.04 \mathrm{~g}$ (between 11.77 and $14.46 \mathrm{~g}$ ), respectively. There were 20 eggs from each EW group used for assessing the egg quality characteristics (10 eggs per EW group). In addition, eggshell conductance and pore concentration were determined for 10 eggs per EW group. The remaining eggs (128 eggs per EW group) in a total of eight setting trays were incubated at a temperature of $37.8^{\circ} \mathrm{C}$ and $60 \%$ relative humidity, and the eggs were turned every $2 \mathrm{~h}$ in a single-stage incubator. Both EW group eggs were divided into two IO groups: non-injection group and injection group, which per IO group had 64 eggs (4 trays with 16 eggs per EW per IO) at day 5 of embryonic age. After $360 \mathrm{~h}$ of incubation, the eggs were candled, and those with living embryos were transferred to the hatcher baskets and maintained at a temperature of $37.0^{\circ} \mathrm{C}$ and $68 \%$ relative humidity. 


\subsection{0 procedure}

A total of 128 eggs per EW group were equally divided into two experimental groups: control (non-injection) group and treatment group (IO injection of $\alpha$-tocopherol) (64 eggs per EW per IO) at day 5 of incubation. Salary et al. (2014), who indicated that IO injection of $15 \mathrm{mg}$ or $30 \mathrm{mg}$ of vitamin E per broiler egg had no affect on broiler performance parameters, while hatchability and post-hatch immunity status had increased by IO injection of $30 \mathrm{mg}$ per egg of vitamin E. We could select to inject $20 \mathrm{mg}$ of vitamin $\mathrm{E}$ per egg if we investigated broiler eggs. The quail egg was $5.36\left(\frac{63 \mathrm{~g} \text { avarage broiler egg weight }}{11.76 \mathrm{~g} \text { avarege quail egg weight }}=5.36\right)$ times smaller than the broiler egg. In this study, $\alpha$-tocopherol injected into each egg was calculated using $\frac{20 \mathrm{mg} \text { vitamin E for broiler egg }}{5.36}=3.75 \mathrm{mg}$ per quail egg (approximative). The volume of IO injection dose was calculated using $3.75 \mathrm{mg} \times 2000 \mu \mathrm{L}$ (vitamin E solution; Evin I.M. $\alpha$-tocopherol acetate sterile solution, Istanbul, Turkey)/300 mg $\alpha$-tocopherol, which was equivalent to a $25 \mu \mathrm{L}$ injection volume. This volume was injected into the yolk sac of each IO egg at day 5 of embryonic age. The large end of each egg (injection site) was sterilised with $70 \%$ ethanol. A $0.5 \mathrm{~mL}$ disposable syringe and a 26-gauge, $13 \mathrm{~mm}$ needle was used for IO injection to the yolk sac. Needle punctures in the eggshell were sealed immediately with sterile paraffin. After injection, the eggs were returned to the incubator.

\subsection{Traits measured}

\subsubsection{Egg characteristics and eggshell temperature}

Prior to incubation, 10 randomly selected eggs from each EW group were used to determine the weights of the egg $(\mathrm{g})$, albumen $(\mathrm{g})$, yolk $(\mathrm{g})$, wet $(\mathrm{g})$ and dry eggshells $(\%)$, egg shape index $(\%)$, eggshell thickness $(\mu \mathrm{m})$, and eggshell surface area $\left(\mathrm{cm}^{2}\right)$ (Peebles and McDaniel, 2004). The $\mathrm{pH}$ values of the albumen and yolk were measured using a $\mathrm{pH}$ meter. The ratio of yolk weight to albumen weight was calculated. Dry eggshell (dried shell plus membranes) weights were presented as percentages of the corresponding EWs. The egg shape index and eggshell surface area were determined using the following formulas: egg shape in$\operatorname{dex}=[$ egg width $(\mathrm{mm}) /$ egg length $(\mathrm{mm})] \times 100]$; eggshell surface area $\left(\mathrm{cm}^{2}\right)=3.9782 \times \mathrm{EW}^{0.7056}$ (Carter, 1975). The average daily egg water loss (mg per day), eggshell conductance (mg per day/torr), relative eggshell conductance (mg per day) and pore concentration were determined using a second set of eggs (10 eggs per EW) according to procedures described by Peebles and McDaniel (2004). The eggshell conductance of each egg based on a saturation vapour conductance of $22.24 \mathrm{~mm} / \mathrm{Hg}$ at $23.6^{\circ} \mathrm{C}$ was calculated by dividing average daily water loss (milligrams per day) by the water vapour pressure gradient (torr) between the inside and outside of the egg. The initial weight of each labelled egg was obtained to $0.0001 \mathrm{~g}$ accuracy before placement in a desiccator, and each egg was reweighed to determine the average daily egg weight loss in the calibrated desiccator, taking into account all recordings of temperature and barometric pressure over 4 days. Relative eggshell conductance was calculated, multiplying by 100 of the eggshell conductance. For measurement of pore concentration, a small hole was cut in the centre of the large end of the eggshell after drying for $3 \mathrm{~h}$ at $50{ }^{\circ} \mathrm{C}$. The eggshell was filled with a dye solution, made by dissolving $0.5 \mathrm{~g}$ of $89 \%$ methylene blue crystals in $1 \mathrm{~L}$ of $70 \%$ ethanol, for $30 \mathrm{~min}$. Pore concentration (number per $0.25 \mathrm{~cm}^{2}$ ) was determined on 10 sections of dyed eggshell pieces from the pointed, equatorial and enlarged areas of the eggshell. The pores in each eggshell region were counted within the marked sections of $0.25 \mathrm{~cm}^{2}$ by using a stereomicroscope with a 40x magnifying lens. The results of the 10 analysed areas per egg were averaged. Eggshell temperatures were measured using a thermocouple (Ebro TFI 250 laser thermometer, 85055 Ingolstadt, Germany) for a total of 80 eggs (five candled eggs from EW for each IO per tray per day) at day $7,9,11,13$ and 15 of incubation.

\subsubsection{Hatching performance}

On day 15 of incubation, living embryos were transferred to the hatcher. A total of 80 eggs (five candled eggs from EW for each IO per tray) were reweighed on day 15 of incubation to calculate the egg water loss: egg water loss $=[(\mathrm{EW}$ of day $0-\mathrm{EW}$ on day 15 of incubation) $/ \mathrm{EW}$ of day 0$] \times 100$. To determine the total incubation duration, eggs were individually assessed every $4 \mathrm{~h}$ from 383 to $411 \mathrm{~h}$ of incubation, and the number of chicks that hatched was recorded. At hatch, the rectal temperature of 10 chicks per subgroup was measured using a thermocouple thermometer inserted approximately $0.8 \mathrm{~cm}$ into the colon. Hatchability was defined as the percentage of hatched chicks per egg set. Eggs that failed to hatch were broken. The non-surviving embryos were divided according to the time of death during embryogenesis: early (before day 6), mid (days 7 to 15), late (after day 15) and pip (pipped shell but not emerged) (Seker et al., 2004). Total embryonic mortalities were calculated. During hatching, chick weight was measured for each newly hatched chick every $4 \mathrm{~h}$ for six measured time points, which were from 387 to $407 \mathrm{~h}$.

\subsubsection{Chick development, morphological traits and relative asymmetry}

At hatch, a total of 80 chicks, comprising five randomly selected chicks from each replicate of the IO subgroups of the EW groups, were removed from the hatcher. Chick length (cm) was measured using a digital calliper $( \pm 0.1 \mathrm{~mm})$. Both sides (left and right of face, middle toe and shank lengths) of bilaterally symmetrical traits were also measured. Face length was measured from ear hole to the merged point of the beak. Middle toe length was measured from the begin- 
ning of the third toe to the tip of the nail on the third toe. Shank length was measured from the top of the tarsometatarsus to the tip of the nail on the third toe. Developmental instability is defined as deviations from symmetrical growth on the right and left sides for any bilateral trait (Yang et al., 1997). Relative asymmetry (RA), which is the absolute value of asymmetry of the left (L) minus the right $(\mathrm{R})$ divided by the size of the mean $\mathrm{L}$ and $\mathrm{R}$ lengths of face, middle toe and shank, was determined using the following formula Eq. (1):

$\mathrm{RA}=\{(\mathrm{L}-\mathrm{R}) /[(\mathrm{L}+\mathrm{R}) / 2]\} \times 100$.

Mean RA was calculated as the average RA of the lengths of the face, middle toe and shank. Chick weight and the weights of the yolk sac, liver, heart, gizzard plus proventriculus and brain were determined for the same chicks. After the chicks were killed by cervical dislocation, the RYS, heart, liver, gizzard plus proventriculus after emptying, and brain were excised from each chick and weighed. Relative weights of the organs and RYS were shown as percentages of the absolute weight of the chick. The RYS, liver and brain were stored at $-55^{\circ} \mathrm{C}$ for further analyses. The remaining chicks for each group were weighed individually from the first hatched to the last hatched every $4 \mathrm{~h}$.

\subsubsection{Antioxidant concentrations in the residual yolk sac and tissues as determined by high-performance liquid chromatography}

The concentrations of total carotenoids and vitamin $\mathrm{E}, \delta$ , $\gamma$-, and $\alpha$-tocopherols, and vitamin A (retinol) in the RYS, liver and brain tissues were determined using methods based on high-performance liquid chromatography (HPLC) (Surai et al., 2001) using a Shimadzu Prominence HPLC instrument. Approximately $250 \mathrm{mg}$ of tissue per RYS sample was thoroughly mixed in $0.7 \mathrm{~mL}$ of $5 \% \mathrm{NaCl}$, followed by the addition of $1 \mathrm{~mL}$ of ethanol and homogenisation $(1 \mathrm{~min})$; during homogenisation, $2 \mathrm{~mL}$ of hexane was added. Samples were centrifuged, and the hexane phase, containing the carotenoids and vitamin E, $\delta-, \gamma-$, and $\alpha-$ tocopherols, and retinol, were collected. The extraction phase with hexane was repeated twice. The combined hexane phases were dried under $\mathrm{N}_{2}$ gas and then redissolved in dichloromethane / methanol $(1: 1 v / v)$ solution. The HPLC system was from Shimadzu (spectrofluorometer, Japan) and fitted with a Hypersil GOLD $5 \mu \mathrm{C} 18$ reverse-phase column $(10 \mathrm{~cm}$ by $4.6 \mathrm{~mm}$; Thermo, US) using a mobile phase of methanol / water $(97: 3 \mathrm{v} / \mathrm{v})$ at a flow rate of $1.05 \mathrm{~mL} \mathrm{~min}^{-1}$. The fluorescence detection of tocopherols and retinols involved excitation and emission wavelengths of 295 and $330 \mathrm{~nm}$, respectively. Standard solutions of tocopherols and retinols in methanol were used for instrument calibration. HPLC analysis of total carotenoids was performed using diode array detection with a mobile phase of methanol / water $(97: 3 v / v)$ at a flow rate of $1.5 \mathrm{~mL} \mathrm{~min}^{-1}$ with a Spherisorb $\mathrm{S}_{5} \mathrm{~N}_{2}, 5 \mu \mathrm{C} 18$ reverse-phase HPLC column ( $25 \mathrm{~cm}$ by $4.6 \mathrm{~mm}$, Phase Separations, Clwyd, UK). Total carotenoids were identified as a single peak at $444 \mathrm{~nm}$, and concentrations were calculated in relation to a lutein standard (Sigma-Aldrich, Poole, UK) (Surai and Sparks, 2001).

\subsection{Statistical analyses}

All of the data were subjected to ANOVA with the general linear model procedure of the JMP statistics package (SAS Institute Inc., 2007). Prior to incubation, the statistical model for the egg characteristics included the EW groups. All of the variables showed normal distributions, except RA, which was transformed to meet a normal distribution by calculating the logarithm base 10 function. Eggshell temperature, hatching performance, morphological traits, RA, chick development and antioxidant concentrations in the RYS and tissues were analysed with a statistical model that included EW group (EWL and EWH) and IO group (control and $\alpha$ tocopherol) and their interaction. Least-squares means were compared using Tukey's test. Differences were considered significant at $P<0.05$.

\section{Results}

\subsection{Effects of EW}

The weights of the albumen, yolk, and wet eggshell and eggshell surface area were significantly higher in the EWH group than in the EWL group. In contrast, the yolk $\mathrm{pH}$ of the EWH group was significantly lower than that of the EWL group (Table 1). However, the egg shape index, yolk weightto-albumen weight ratio, dry eggshell weight, eggshell thickness, average daily egg water loss, eggshell conductance, relative eggshell conductance, albumen $\mathrm{pH}$ and pore concentration were not affected by EW (Table 1). Eggshell temperature values were presented in Table 2. Eggshell temperature was higher in the EWL group than in the EWH group at days 7, 9 and 11 of incubation $(P<0.05)$. In contrast, eggshell temperature was lower in the EWL group than in the EWH group at day 15 of incubation. Egg water loss was $11.27 \pm 0.70 \%$ in the EWL group and $12.87 \pm 0.71 \%$ in the EWH group $(P=0.114)$. Rectal temperature and the hatching performance parameters were similar among the EW groups (Table 2). Chick weight was significantly higher in the EWH group than in the EWL group every $4 \mathrm{~h}$ after hatching for a total of six measured time points $(P<0.001$; Table 2$)$. Average chick weight and the weights of the RYS ( $g$ and \%) and liver (g) were significantly lower for the EWL group than for the EWH group, whereas the weight of the gizzard plus proventriculus (\%) was significantly higher for the EWL group than for the EWH group (Table 3). Middle toe length, RA of shank length and mean RA were significantly lower in the EWH group than in the EWL group (Table 3). EW had no effect on the weight of liver (\%), heart ( $\mathrm{g}$ and \%), brain ( $\mathrm{g}$ and \%) or 
Table 1. The effect of egg weight on egg quality characteristics prior to incubation of hatching eggs in the breeder quail.

\begin{tabular}{|c|c|c|c|c|}
\hline & \multicolumn{2}{|c|}{ EW } & \multirow[b]{2}{*}{ SEM } & \multirow[b]{2}{*}{$P$ value } \\
\hline & $<11.76$ & $>11.76$ & & \\
\hline \multicolumn{5}{|l|}{ Egg quality characteristics } \\
\hline Egg weight $(g)$ & 10.60 & 12.50 & 0.10 & $<0.001$ \\
\hline Egg shape index $(\%)$ & 77.60 & 77.00 & 0.60 & 0.496 \\
\hline Albumen weight (g) & 5.42 & 6.42 & 0.10 & $<0.001$ \\
\hline Yolk weight $(\mathrm{g})$ & 3.63 & 4.36 & 0.90 & 0.002 \\
\hline Yolk weight / albumen weight & 0.67 & 0.68 & 0.03 & 0.887 \\
\hline Wet eggshell weight (g) & 1.50 & 1.63 & 0.04 & 0.031 \\
\hline Dry eggshell weight (\%) & 7.84 & 7.42 & 0.20 & 0.172 \\
\hline Eggshell thickness $(\mu)$ & 0.21 & 0.20 & 0.02 & 0.610 \\
\hline Eggshell surface area $\left(\mathrm{cm}^{2}\right)$ & 21.10 & 23.60 & 0.20 & $<0.001$ \\
\hline Daily egg water loss (mg/d) & 29.50 & 28.10 & 2.50 & 0.707 \\
\hline Eggshell conductance (EC) (mg per day/torr) & 1.61 & 1.54 & 0.10 & 0.707 \\
\hline Relative EC (mg per day/torr) & 14.88 & 12.19 & 1.20 & 0.118 \\
\hline Albumen $\mathrm{pH}$ & 9.32 & 9.25 & 0.03 & 0.157 \\
\hline Yolk pH & 6.58 & 6.28 & 0.07 & 0.005 \\
\hline Pore concentration (number/ $0.25 \mathrm{~cm}^{2}$ ) & 21.45 & 19.32 & 0.99 & 0.804 \\
\hline
\end{tabular}

EW: egg weight. SEM: standard error of the mean.

Table 2. The effects of egg weight and in ovo administration of $\alpha$-tocopherol on eggshell temperature at days 7,9,11,13 and 15 of incubation, rectal temperature, hatching time, hatchability, embryonic mortalities and chick weight in the quail.

\begin{tabular}{|c|c|c|c|c|c|c|c|c|c|}
\hline & \multicolumn{2}{|c|}{ EW } & \multirow[b]{2}{*}{ SEM } & \multicolumn{2}{|r|}{$\mathrm{IO}$} & \multirow[b]{2}{*}{ SEM } & \multicolumn{3}{|c|}{$P$ value } \\
\hline & $<11.76$ & $>11.76$ & & Control & $\alpha$-tocopherol & & EW & IO & $\mathrm{EW}^{*} \mathrm{IO}$ \\
\hline \multicolumn{10}{|l|}{ Eggshell temperature $\left({ }^{\circ} \mathrm{C}\right)$} \\
\hline Day 7 & 36.01 & 34.59 & 0.13 & 34.76 & 35.84 & 0.14 & $<0.001$ & $<0.001$ & 0.788 \\
\hline Day 9 & 36.46 & 36.02 & 0.08 & 35.75 & 36.73 & 0.08 & 0.004 & $<0.001$ & $<0.001$ \\
\hline Day 11 & 37.69 & 36.91 & 0.05 & 37.34 & 37.26 & 0.05 & $<0.001$ & 0.285 & 0.026 \\
\hline Day 13 & 37.28 & 37.30 & 0.09 & 37.45 & 37.12 & 0.09 & 0.859 & 0.012 & 0.001 \\
\hline Day 15 & 37.84 & 38.23 & 0.13 & 38.06 & 38.00 & 0.13 & 0.043 & 0.766 & 0.049 \\
\hline Rectal temperature $\left({ }^{\circ} \mathrm{C}\right)$ & 36.42 & 36.83 & 0.18 & 36.79 & 36.46 & 0.18 & 0.111 & 0.196 & 0.990 \\
\hline Hatching time (hours) & 394.00 & 392.00 & 1.00 & 391.00 & 395.00 & 1.00 & 0.116 & 0.011 & 0.020 \\
\hline Hatchability $^{1}(\%)$ & 84.91 & 80.62 & 5.21 & 79.05 & 85.97 & 4.56 & 0.513 & 0.786 & 0.503 \\
\hline \multicolumn{10}{|l|}{ Embryonic mortalities (\%) } \\
\hline Early & 4.31 & 11.31 & 3.60 & 9.65 & 6.48 & 3.66 & 0.268 & 0.584 & 0.924 \\
\hline Mid & 3.27 & 6.04 & 3.31 & 5.89 & 3.42 & 2.98 & 0.540 & 0.584 & 0.515 \\
\hline Late & 7.51 & 2.03 & 2.47 & 5.41 & 4.13 & 1.76 & 0.143 & 0.425 & 0.847 \\
\hline Total $^{2}$ & 15.09 & 19.38 & 5.07 & 20.95 & 14.03 & 4.11 & 0.680 & 0.389 & 0.479 \\
\hline \multicolumn{10}{|l|}{ Chick weight (g) } \\
\hline $387^{3}$ & $7.81^{\mathrm{b}}$ & $8.96^{\mathrm{a}}$ & 0.18 & 8.58 & 8.19 & 0.20 & 0.001 & 0.229 & 0.624 \\
\hline 391 & $7.70^{\mathrm{b}}$ & $8.79^{\mathrm{a}}$ & 0.11 & 8.37 & 8.13 & 0.12 & $<0.001$ & 0.142 & 0.125 \\
\hline 395 & $7.64^{\mathrm{b}}$ & $8.87^{\mathrm{a}}$ & 0.15 & 8.44 & 8.07 & 0.16 & $<0.001$ & 0.102 & 0.817 \\
\hline 399 & $7.50^{\mathrm{b}}$ & $8.73^{\mathrm{a}}$ & 0.09 & 8.12 & 8.12 & 0.09 & $<0.001$ & 0.990 & 0.165 \\
\hline 403 & $7.64^{\mathrm{b}}$ & $8.73^{\mathrm{a}}$ & 0.16 & 8.05 & 8.32 & 0.17 & $<0.001$ & 0.256 & 0.064 \\
\hline 407 & $7.69^{b}$ & $8.76^{\mathrm{a}}$ & 0.16 & $8.54^{\mathrm{a}}$ & $7.91^{\mathrm{b}}$ & 0.16 & $<0.001$ & 0.008 & 0.405 \\
\hline
\end{tabular}

EW: egg weight. IO: in ovo administration. SEM: standard error of the mean. ${ }^{1}$ Hatchability: hatched chick number / fertilised egg number $\cdot 100 .{ }^{2}$ The pip dead was not included in total dead. ${ }^{3}$ Hours: measured hour for each newly hatched chick. 
Table 3. The effects of egg weight and in ovo administration of $\alpha$-tocopherol on weights of the chick, residual yolk sac, liver, heart, gizzard plus proventriculus, and brain during development and on morphological traits, relative asymmetry and mean relative asymmetry of bilateral traits in the quail chick.

\begin{tabular}{|c|c|c|c|c|c|c|c|c|c|}
\hline & \multicolumn{2}{|c|}{ EW } & \multirow[b]{2}{*}{ SEM } & \multicolumn{2}{|r|}{ IO } & \multirow[b]{2}{*}{ SEM } & \multicolumn{3}{|c|}{$P$ value } \\
\hline & $<11.76$ & $>11.76$ & & Control & $\alpha$-tocopherol & & EW & IO & $\mathrm{EW}^{*} \mathrm{IO}$ \\
\hline \multicolumn{10}{|l|}{ Chick development } \\
\hline Chick weight (g) & 7.27 & 8.38 & 0.15 & 8.00 & 8.65 & 0.15 & $<0.001$ & 0.108 & 0.580 \\
\hline RYS (g) & 0.38 & 0.65 & 0.05 & 0.54 & 0.49 & 0.05 & 0.001 & 0.545 & 0.350 \\
\hline RYS (\%) & 5.19 & 7.74 & 0.62 & 6.62 & 6.31 & 0.62 & 0.006 & 0.722 & 0.667 \\
\hline Liver $(\mathrm{g})$ & 0.22 & 0.25 & 0.01 & 0.26 & 0.22 & 0.01 & 0.002 & 0.006 & 0.884 \\
\hline Liver $(\%)$ & 2.99 & 2.97 & 0.09 & 3.08 & 2.89 & 0.09 & 0.875 & 0.109 & 0.842 \\
\hline Heart (g) & 0.08 & 0.09 & 0.02 & 0.10 & 0.07 & 0.02 & 0.121 & 0.002 & 0.800 \\
\hline Heart $(\%)$ & 1.14 & 1.08 & 0.04 & 1.20 & 1.02 & 0.04 & 0.421 & 0.008 & 0.899 \\
\hline Gizzard plus proventriculus (g) & 0.47 & 0.48 & 0.01 & 0.47 & 0.47 & 0.01 & 0.347 & 0.344 & 0.063 \\
\hline Gizzard plus proventriculus (\%) & 6.49 & 5.82 & 0.16 & 6.14 & 6.17 & 0.16 & 0.006 & 0.891 & 0.048 \\
\hline Brain $(\mathrm{g})$ & 0.25 & 0.27 & 0.01 & 0.27 & 0.26 & 0.01 & 0.159 & 0.347 & 0.708 \\
\hline Brain $(\%)$ & 3.50 & 3.30 & 0.13 & 3.42 & 3.39 & 0.12 & 0.284 & 0.868 & 0.615 \\
\hline \multicolumn{10}{|c|}{ The lengths of bilateral morphological traits } \\
\hline Chick length (cm) & 11.67 & 11.85 & 0.13 & 11.56 & 11.96 & 0.12 & 0.332 & 0.028 & 0.667 \\
\hline Face length (mm) & 8.22 & 8.23 & 0.20 & 8.31 & 8.14 & 0.20 & 0.982 & 0.570 & 0.589 \\
\hline Middle toe length (mm) & 12.58 & 11.75 & 0.27 & 11.56 & 12.77 & 0.27 & 0.037 & 0.003 & 0.842 \\
\hline Shank length $(\mathrm{mm})$ & 10.3 & 9.8 & 0.28 & 10.84 & 9.26 & 0.28 & 0.217 & 0.001 & 0.016 \\
\hline \multicolumn{10}{|l|}{$\mathrm{RA}^{*}$} \\
\hline Face length & 0.65 & 0.15 & 0.21 & 0.49 & 0.31 & 0.21 & 0.103 & 0.562 & 0.844 \\
\hline Middle toe length & 0.53 & 0.46 & 0.19 & 0.67 & 0.32 & 0.20 & 0.816 & 0.199 & 0.068 \\
\hline Shank length & 1.53 & 0.63 & 0.36 & 0.48 & 1.12 & 0.34 & 0.007 & 0.218 & 0.299 \\
\hline Mean RA & 0.90 & 0.23 & 0.16 & 0.54 & 0.58 & 0.16 & 0.005 & 0.862 & 0.110 \\
\hline
\end{tabular}

EW: egg weight. IO: in ovo administration. EM: standard error of the mean. RYS: residual yolk sac. ${ }^{*}$ RA: relative asymmetry, calculated as [ left - right $\mid /($ left + right $) / 2] \cdot 100$.

gizzard plus proventriculus (g). The lengths of the chick, face and shank and the RA of face and middle toe lengths did not differ among the EW groups (Table 3). Total retinol, $\delta$ - and $\alpha$-tocopherol concentrations of the RYS were significantly higher in the EWH group than in the EWL group, whereas total carotenoid concentration of the RYS was significantly lower in the EWH group than in the EWL group (Table 4). Heavy eggs showed significantly higher total retinol and $\delta$ tocopherol concentrations in the liver than light eggs (Table 4). In contrast, the total carotenoids and $\gamma$-tocopherol concentrations in the liver were significantly lower in the EWH group than in the EWL group (Table 4). A similar pattern of change was observed for total carotenoids and $\delta$ - and $\gamma$-tocopherol concentrations in the brain (Table 4). However, there was no effect of EW on $\gamma$-tocopherol concentration in the RYS, $\alpha$-tocopherol concentration in the liver, or retinol and $\alpha$-tocopherol concentrations in the brain. No significant difference was found between the EWL and EWH groups for total vitamin E concentration in the RYS, liver or brain (Table 4).

\subsection{Effects of IO $\alpha$-tocopherol}

Eggshell temperature was higher in the $\alpha$-tocopherol group than the control group at days 7 and 9 of incubation but was lower in the $\alpha$-tocopherol group than the control group at day 13 of incubation $(P<0.05$; Table 2). Egg water loss was $12.58 \pm 0.69 \%$ in the control group and $11.56 \pm 0.70 \%$ in the $\alpha$-tocopherol group $(P=0.308)$. Hatching time was significantly prolonged in the $\alpha$-tocopherol group compared with the control group (Table 2). Rectal temperature, hatchability, and embryo mortalities were not affected by IO $\alpha$ tocopherol administration (Table 2).

Newly hatched chick weight after hatching was decreased in the $\alpha$-tocopherol group compared to the control group only at $407 \mathrm{~h}$ (Table 2). IO $\alpha$-tocopherol administration significantly affected the absolute weights of the liver and heart and the relative weight of the heart, which were lower in the $\alpha$ tocopherol group than in the control group (Table 3). Chick length and middle toe length were significantly higher in the $\alpha$-tocopherol group than in the control group. In contrast, shank length was significantly shorter in the $\alpha$-tocopherol group than in the control group (Table 3). IO $\alpha$-tocopherol 
Table 4. The effects of egg weight and in ovo administration of $\alpha$-tocopherol on the concentrations of total retinol, total carotenoids, $\delta$-, $\gamma$-, and $\alpha$-tocopherols, and vitamin $\mathrm{E}$ in the residual yolk sac, liver and brain of the quail chick.

\begin{tabular}{|c|c|c|c|c|c|c|c|c|c|}
\hline & \multicolumn{2}{|c|}{ EW } & \multirow[b]{2}{*}{ SEM } & \multicolumn{2}{|r|}{ IO } & \multirow[b]{2}{*}{ SEM } & \multicolumn{3}{|c|}{$P$ value } \\
\hline & $<11.76$ & $>11.76$ & & Control & $\alpha$-tocopherol & & EW & IO & $\mathrm{EW} * \mathrm{IO}$ \\
\hline \multicolumn{10}{|c|}{ Retinol $\left(\mu \mathrm{g} \mathrm{g}^{-1}\right)$} \\
\hline RYS & 0.87 & 1.79 & 0.12 & 1.43 & 1.15 & 0.16 & 0.009 & 0.227 & 0.862 \\
\hline Liver & 0.26 & 0.71 & 0.05 & 0.53 & 0.45 & 0.05 & $<0.001$ & 0.319 & 0.863 \\
\hline Brain & 0.069 & 0.074 & 0.01 & 0.073 & 0.071 & 0.01 & 0.722 & 0.892 & 0.123 \\
\hline \multicolumn{10}{|c|}{ Carotenoids $\left(\mu \mathrm{g} \mathrm{g}^{-1}\right)$} \\
\hline RYS & 142.52 & 104.78 & 13.0 & 112.18 & 135.13 & 12.9 & 0.045 & 0.215 & 0.234 \\
\hline Liver & 40.61 & 30.16 & 2.40 & 32.96 & 37.82 & 2.3 & 0.004 & 0.157 & 0.996 \\
\hline Brain & 7.67 & 3.01 & 0.55 & 5.6 & 5.08 & 0.55 & $<0.001$ & 0.505 & 0.545 \\
\hline \multicolumn{10}{|c|}{$\delta$-tocopherol $\left(\mu \mathrm{g} \mathrm{g}^{-1}\right)$} \\
\hline RYS & 7.33 & 14.89 & 1.08 & 9.21 & 13.01 & 1.09 & $<0.001$ & 0.017 & 0.872 \\
\hline Liver & 1.56 & 2.57 & 0.20 & 1.70 & 2.43 & 0.20 & 0.001 & 0.014 & 0.349 \\
\hline Brain & 4.17 & 2.78 & 0.19 & 2.85 & 4.09 & 0.23 & 0.001 & 0.006 & 0.186 \\
\hline \multicolumn{10}{|c|}{$\gamma$-tocopherol $\left(\mu \mathrm{g} \mathrm{g}^{-1}\right)$} \\
\hline RYS & 291.82 & 294.89 & 27.2 & 260.11 & 326.6 & 27.2 & 0.937 & 0.093 & 0.918 \\
\hline Liver & 97.53 & $77.82^{\mathrm{b}}$ & 5.52 & 80.89 & 94.45 & 5.32 & 0.013 & 0.080 & 0.084 \\
\hline Brain & 0.48 & $0.33^{\mathrm{b}}$ & 0.04 & 0.40 & 0.41 & 0.04 & 0.023 & 0.889 & 0.065 \\
\hline \multicolumn{10}{|c|}{$\alpha$-tocopherol $\left(\mu \mathrm{g} \mathrm{g}^{-1}\right)$} \\
\hline RYS & 682.27 & 892.20 & 56.9 & 676.88 & 897.59 & 56.9 & 0.013 & 0.009 & 0.106 \\
\hline Liver & 345.80 & 327.24 & 12.14 & 309.26 & 363.78 & 12.1 & 0.287 & 0.003 & 0.340 \\
\hline Brain & 11.49 & 12.20 & 0.84 & 9.85 & 13.84 & 0.82 & 0.552 & 0.002 & 0.015 \\
\hline \multicolumn{10}{|c|}{$\operatorname{Vitamin} E\left(\mu \mathrm{g} \mathrm{g}^{-1}\right)$} \\
\hline RYS & 981.56 & 1201.13 & 81.5 & 946.20 & 1237.20 & 81.5 & 0.063 & 0.016 & 0.241 \\
\hline Liver & 444.89 & 407.63 & 15.9 & 391.85 & 460.67 & 15.8 & 0.106 & 0.004 & 0.895 \\
\hline Brain & 16.10 & 15.32 & 1.03 & 13.10 & 18.31 & 1.00 & 0.595 & 0.001 & 0.029 \\
\hline
\end{tabular}

EW: egg weight. IO: in ovo administration. SEM: standard error of the mean. RYS: residual yolk sac.

had no effects on the weights of chick, RYS ( $\mathrm{g}$ and \%), liver $(\%)$, brain (g and \%), gizzard plus proventriculus (g and \%), face length, RA, and mean RA of the examined bilateral traits (Table 3). Delta- and $\alpha$-tocopherols and vitamin E concentrations in the RYS, liver and brain were significantly higher following treatment with $\mathrm{IO} \alpha$-tocopherol than in the control group (Table 4). There was no effect of $\alpha$-tocopherol administration on total retinol, total carotenoids or the $\gamma$-tocopherol concentrations of the RYS, liver and brain (Table 4).

\subsection{Interaction effects of EW and IO tocopherol}

A significant interaction between EW and IO for eggshell temperature occurred at days 9, 11, 13 and 15 of incubation (Tables 2, 5). Although eggshell temperature was higher in the $\alpha$-tocopherol group than the control group within the EWL group at day 9 of incubation, it was lower in the $\alpha$ tocopherol group than control group within the EWH group at days 11 and 13 of incubation $(P<0.05)$ (Table 5). At day 15 of incubation, eggshell temperature was the highest for control eggs of the EWH group and the lowest for control eggs of the EWL group $(P<0.05)$; however, no significant difference between the two EW groups was observed for the IO $\alpha$-tocopherol eggs (Table 5). IO administration did not interact with EW for the weights of chick, RYS, liver, heart and brain, but an interaction effect on relative gizzard plus proventriculus weight was observed (Table 3). This significant interaction was due to the $\alpha$-tocopheroltreated EWH chicks having lower gizzard plus proventriculus weights and the control and $\alpha$-tocopherol-treated EWL chicks having higher gizzard plus proventriculus weights (Table 5). There was a significant interaction among EW and IO for shank length (Table 3). Shank length was greater in control chicks than $\alpha$-tocopherol-treated chicks within the EWL group, whereas no such difference was observed in 
Table 5. Interaction effect of egg weight and in ovo administration of $\alpha$-tocopherol on the eggshell temperature at days $9,11,13$ and 15 of incubation in the quail embryo, gizzard plus proventriculus weight, shank length, hatching time and brain $\alpha$-tocopherol and vitamin E levels in the quail chicks.

\begin{tabular}{|c|c|c|c|c|c|}
\hline & \multicolumn{4}{|c|}{ EW } & \multirow[b]{4}{*}{ SEM } \\
\hline & \multicolumn{2}{|c|}{$<11.76$} & \multicolumn{2}{|c|}{$>11.76$} & \\
\hline & \multicolumn{4}{|c|}{ IO } & \\
\hline & Control & $\alpha$-tocopherol & Control & $\alpha$-tocopherol & \\
\hline \multicolumn{6}{|l|}{ Eggshell temperature $\left({ }^{\circ} \mathrm{C}\right)$} \\
\hline Day 9 & $35.63^{\mathrm{c}}$ & $37.29^{\mathrm{a}}$ & $35.87^{b}$ & $36.17^{\mathrm{bc}}$ & 0.11 \\
\hline Day 11 & $37.64^{\mathrm{a}}$ & $37.73^{\mathrm{a}}$ & $37.03^{\mathrm{b}}$ & $36.79^{\mathrm{c}}$ & 0.07 \\
\hline Day 13 & $37.20^{\mathrm{bc}}$ & $37.35^{\mathrm{b}}$ & $37.71^{\mathrm{a}}$ & $36.89^{\mathrm{c}}$ & 0.10 \\
\hline Day 15 & $37.68^{\mathrm{b}}$ & $38.00^{\mathrm{ab}}$ & $38.44^{\mathrm{a}}$ & $38.01^{\mathrm{ab}}$ & 0.17 \\
\hline Gizzard plus proventriculus (\%) & $6.71^{\mathrm{a}}$ & $6.27^{\mathrm{a}}$ & $6.07^{\mathrm{ab}}$ & $5.57^{\mathrm{b}}$ & 0.25 \\
\hline Shank length (mm) & $10.70^{\mathrm{a}}$ & $9.01^{\mathrm{b}}$ & $10.09^{\mathrm{b}}$ & $10.57^{\mathrm{ab}}$ & 0.40 \\
\hline Hatching time (hours) & $390^{\mathrm{b}}$ & $395^{\mathrm{a}}$ & $394^{\mathrm{a}}$ & $394^{\mathrm{a}}$ & 1.00 \\
\hline Brain $\alpha$-tocopherol $\left(\mu \mathrm{g} \mathrm{g}^{-1}\right)$ & $11.72^{\mathrm{ab}}$ & $12.68^{\mathrm{a}}$ & $7.98^{\mathrm{b}}$ & $14.99^{\mathrm{a}}$ & 1.19 \\
\hline Brain vitamin $\mathrm{E}\left(\mu \mathrm{g} \mathrm{g}^{-1}\right)$ & $14.38^{\mathrm{bc}}$ & $16.26^{\mathrm{ab}}$ & $11.84^{\mathrm{c}}$ & $20.37^{\mathrm{a}}$ & 1.46 \\
\hline
\end{tabular}

a, b, c Least-square means for the same line differ significantly $(P<0.05)$. EW: egg weight. IO: in ovo administration. SEM: standard error of the mean.

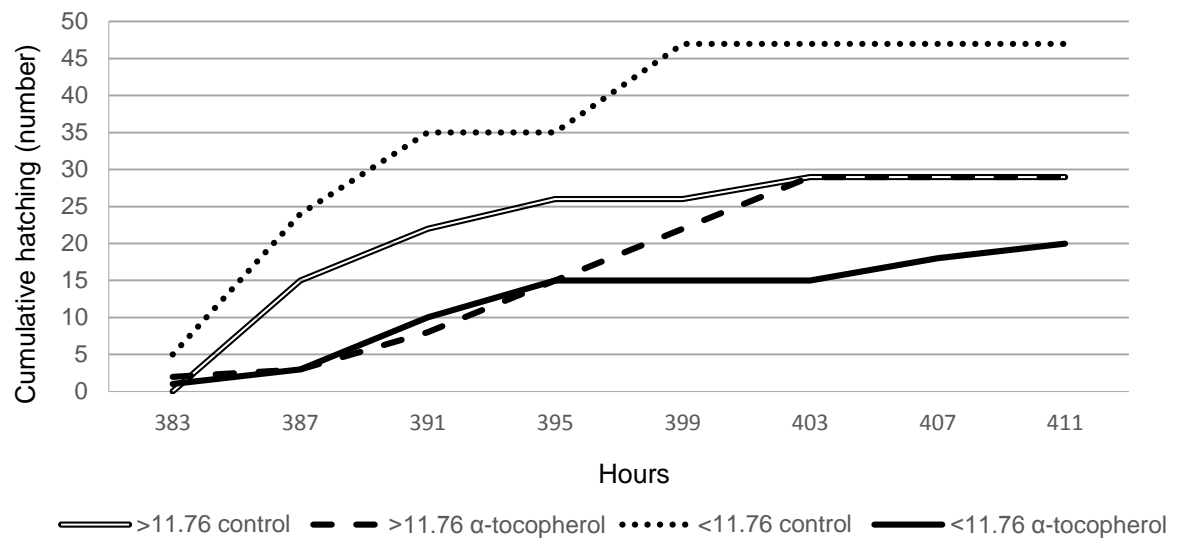

Figure 1. The effects of egg weight $(<11.76,>11.76)$ and in ovo administration (control, $\alpha$-tocopherol) on the cumulative hatching of quail chicks.

the EWH group (Table 5). Hatching time of the $\alpha$-tocopherol group was delayed by approximately $5 \mathrm{~h}$ relative to hatching time of the non-injected chicks in the EWL group (Table 5). Cumulative hatching within $10 \mathrm{~h}$ after hatching was higher in the control group than in the $\alpha$-tocopherol-treated group in both EW groups, but these differences were not significant (Fig. 1). The interaction between EW and IO was significant for the brain concentrations of $\alpha$-tocopherol $(P=0.015)$ and vitamin $\mathrm{E}(P=0.029)$. For brain $\alpha$-tocopherol concentration, this interaction reflected the occurrence of the highest $\alpha$-tocopherol concentration in the $\alpha$-tocopherol-treated EWH chicks, whereas in the EWL chicks, the concentration did not differ between the IO groups (Table 5). Whereas vitamin E concentration was similar between the control and $\alpha$ tocopherol chicks within the light EW group, it was signifi- cantly higher in the $\alpha$-tocopherol chicks than in the control chicks within the EWH group (Table 5).

\section{Discussion}

In this experiment, yolk and wet eggshell weights and eggshell surface area values increased significantly with increasing EW (above $11.76 \mathrm{~g}$ ). These results are consistent with results of Ashraf et al. (2016). Ashraf et al. (2016) also reported a lower yolk $\mathrm{pH}$ in lighter eggs than in heavier eggs, which is inconsistent with our results. The results of this study showed that the newly hatched weights of chicks from heavier eggs were significantly greater than those of chicks from lighter eggs every $4 \mathrm{~h}$ at the six measured time points. Egg weight increases in a linear manner 
with increasing breeding age as described by Yannakopoulos and Tserveni-Gousi (1987), and it has a direct influence on chick development. Due to increasing breeder quail age, significant variation in chick weight was observed from day 72 (EW between 8.21 and $11.75 \mathrm{~g}$ ) to day 128 (EW between 11.77 and $14.46 \mathrm{~g}$ ) of breeder quail age. As EW increases, heavier eggs begin to exhibit a higher eggshell surface area than lighter eggs, as reported by Shafey (2002). Lower amounts of egg water loss per square centimetre of surface area of eggshell were exhibited by heavier eggs compared with lighter eggs; however, this difference did not contribute to differences in embryonic mortality in the current study. The main reason for this is that average daily water loss did not differ among the groups because pore concentration, conductance and thickness of the eggshell remained similar among the EW groups. In the present study, the absolute and relative RYS weights were increased in heavier eggs, which is consistent with Peebles et al. (2000). In addition, the increased absolute liver weight and higher eggshell temperatures of the embryos from heavier eggs during late embryonic development might be related to differences in embryonic metabolism. This assumption is supported by O'dea et al. (2004), who found higher metabolic activity in heavier chicks; however, in our results, a lower RYS was observed in chicks from lighter eggs, reflecting the more rapid utilisation of nutrients. Moreover, in this study, eggshell temperatures were greater for the embryos of IO $\alpha$-tocopherol-treated lighter eggs than those of similarly treated heavier eggs at days 9 and 11 of incubation. These results indicated that the IO injection of $\alpha$-tocopherol into the yolk sac might have enhanced the metabolism of embryos from the light quail eggs by affecting the transfer of $\alpha$-tocopherol from the yolk sac to the tissues before hatching. However, hatching time was prolonged in the $\alpha$-tocopherol-treated chicks from the light quail eggs. This prolonged hatching time might have been due to high sensitivity of the embryos of lighter eggs to IO administration of $\alpha$-tocopherol. This high sensitivity might be associated with the slightly higher plasma corticosterone concentration of chicks at hatch (Babacanoğlu and Yalçın, 2014).

The chick and middle toe lengths were the greatest for chicks that received IO $\alpha$-tocopherol administration on day 5 of embryo development. These results indicate that IO $\alpha$ tocopherol administration had positive effects on chick quality without affecting the developmental stability of the measured bilateral morphological traits. However, shank length was affected negatively by IO $\alpha$-tocopherol administration, although its RA value was unaffected in the newly hatched quail chicks. This study is the first report on the effects of IO $\alpha$-tocopherol injection on chick length and the RA values of the shank, middle toe and face lengths of quail at hatch. Middle toe length was decreased in the chicks from heavy eggs, whereas its RA was not affected by EW; however, the highest mean RA and the RA of shank length were observed in the chicks from light eggs in this study. The effects of EW on the
RA of shank length and mean RA indicated that developmental instability of shank length can be promoted by a decreased egg weight in hatched quail chicks. Our results showed that there was no effect of IO $\alpha$-tocopherol injection on hatchability. This result is consistent with Schaal (2008), who obtained a similar result with IO vitamin E injection. Our findings indicated that the total retinol concentrations of RYS and liver were higher in the heavier eggs, whereas the total carotenoid concentrations in all tissues and RYS were lower in the heavier eggs. These findings might be a result of vitamin A deficiency in the heavier eggs. Similarly, Hudon (1994) reported that carotenoids in heavier eggs could be converted to vitamin A. The low total carotenoid concentrations in the RYS and embryo tissues from heavier eggs might reflect the fact that total carotenoids can be efficiently converted to vitamin A (retinol), as reported by Burley and Vadehra (1989). Therefore, the newly hatched quail chick may convert appropriate carotenoids to vitamin $\mathrm{A}$ in the liver and RYS.

In this study, IO $\alpha$-tocopherol injection into the yolk sac of the large egg increased $\alpha$-tocopherol and vitamin E concentrations in brain tissues. The accumulation and concentration of lipid-soluble antioxidants in embryonic tissues may have adaptive significance in providing protection to PUFAs against peroxidation, particularly at hatching (Surai, 2002). It has been reported that large amounts of vitamin $\mathrm{E}$ accumulation may occur with a high PUFA in the lipid fraction of brain; therefore, lipids play an important role in vitamin E solubilisation and subsequent absorption (Surai, 2002; Surai et al., 2016). This observation was confirmed by Schaal (2008), who concluded that chicks injected with vitamin $\mathrm{E}$ had increased relative brain weight and brain total lipid level to protect lipid membranes from the harmful effects of radical oxygen species and allow for increased lipid utilisation for energy production.

The cooperative interaction between antioxidants in the cell is vital for maximum protection from the detrimental effects of free radicals (Surai, 2002). Oxidised vitamin E can be converted back into the active reduced form by reacting with other antioxidants, such as carotenoids (Palozza and Krinsky, 1992; Bohm et al., 1997). Increasing the dietary carotenoid concentration of the maternal diet was associated with increased vitamin E concentrations in the egg yolk and embryonic tissues and their increased resistance to oxidative stress (Surai and Speake, 1998; Surai et al., 2003, 2016). Therefore, we hypothesised that IO administration of $\alpha$-tocopherol might increase the carotenoid concentration in embryonic tissues. However, IO $\alpha$-tocopherol injection did not affect the total carotenoid concentration in the tissues of quail chicks in the present study. Our result is consistent with Frigg et al. (1992), who concluded that the carotenoid concentration of the yolk was unaffected by dietary $\alpha$-tocopherol. Thus, neither dietary nor IO administration of $\alpha$-tocopherol affected the carotenoid concentrations of chick tissues, with no effect of $\alpha$-tocopherol on the carotenoid concentrations in the RYS in the present study. Similar results were reported 
by Possenti et al. (2017), who tested the effect of in ovo vitamin $\mathrm{E}$ on the distribution and use of other antioxidants and on oxidative status markers in the yolk and focal organs. They found that embryo growth was positively associated with antioxidant concentrations; however, an experimental increase in egg vitamin $E$ level did not affect the relationships between other antioxidants or the markers of oxidative status and vitamin E concentration. In addition, in the present study, the highest vitamin $\mathrm{E}$ and $\alpha$-tocopherol concentrations occurred in the order of RYS < liver < brain. Surai (2002) reported that the highest $\alpha$-tocopherol concentration was found in the liver and that the lowest was found in the heart. This tissue specificity of $\alpha$-tocopherol accumulation demonstrates that the location (yolk, albumen, amnion) and timing (embryo age) of $\alpha$-tocopherol injection might affect reduced heart and liver weights following the injection of $\alpha$-tocopherol on day 5 into the yolk sac in this study. Moreover, the reduced liver weight observed for the $\alpha$-tocopherol-treated chicks at hatch was likely due to lower fat metabolism in these chicks relative to controls.

The results indicated that IO $\alpha$-tocopherol injection might improve embryonic metabolism without affecting chick development in light quail eggs, whereas it might increase the concentrations of $\alpha$-tocopherol and vitamin $\mathrm{E}$ in the brain tissues without affecting hatching performance in chicks from heavy quail eggs. In conclusion, IO $\alpha$-tocopherol injection into the yolk sac and EW can affect the lipidsoluble antioxidant-specific and tissue-specific concentrations of lipid-soluble antioxidants in the tissues of newly hatched quail chicks.

Data availability. The data sets are available upon request to the corresponding author.

Author contributions. EB and MRK designed the hypothesis of this result. Data collection was obtained and statistical analysis was performed by EB and MRK. HPLC-based methods for concentrations of lipid-soluble antioxidants were performed by MRK and FK.

Competing interests. The authors declare that they have no conflict of interest.

Acknowledgements. The authors especially thank İbrahim Özdemir, who helped with the experiment.

Edited by: Manfred Mielenz

Reviewed by: two anonymous referees

\section{References}

Ashraf, S., Javid, A., Ashraf, M., Akram, M., Malik, S., Irfan, and Altaf, M.: Influence of egg weight on egg quality parameters and growth traits in ring necked pheasants (phasianus colchicus) in captivity, J. Anim. Plant Sci., 26, 331-338, 2016.

Babacanoğlu, E. and Yalçın, S.: Hormone-mediated maternal stress affects embryonic development during incubation without adverse effect on chick weight and body composition, Brit. Poultry Sci., 55, 186-193, 2014.

Bohm, F., Edge, R. L., Edge, E. J., McGarvey, D. J., and Truscott, T. G.: Carotenoids enhance vitamin E antioxidant efficiency, Journal of American Chemical Society, 119, 621-622, 1997.

Burley, R. W. and Vadehra, D. V.: An outline of the physiology of avian egg formation and emmbryogenesis in avian eggs. The avian egg: chemistry and biology, 17-288, John Wiley \& Sons, New York, USA, 1989.

Carter, T. C.: The hen's egg: estimation of shell superficial area and egg volume, using measurements of fresh egg weight and shell length and breadth alone or in combination, Brit. Poultry Sci., $16,541-543,1975$.

Frigg, M., Whitehead, C. C., and Weber, S.: Absence of effects of dietary $\alpha$-tocopherol on egg yolk pigmentation, Brit. Poultry Sci., 33, 347-353, 1992.

Gaál, T., Mézes, M., Noble, R. C., Dixon, J., and Speake, B. K.: Development of antioxidant capacity in tissues of the chick embryo, Comp. Biochem. Phys. B, 112, 711-716, 1995.

Hossain, S. M., Barreto, S. L., Bertechini, A. G., Rios, A. M., and Silva, C. G.: Influence of dietary Vitamin E level on egg production of broiler breeders, and on the growth and immune response of progeny in comparison with the progeny from eggs injected with Vitamin E, Anim. Feed Sci. Tech., 73, 307-317, 1998.

Hudon, J.: Biotechnological applications of research on animal pigmentation, Biotechnol. Adv., 12, 49-69, 1994.

Ionov, I., Surai, P. F., and Sakhatsky, N.: Vitamins A and E content in avian egg yolk, J. Ornithol., 135, p. 52, 1994.

Karadas, F., Surai, P. F., and Sparks, N. H.: Changes in broiler chick tissue concentrations of lipid-soluble antioxidants immediately post-hatch, Comp. Biochem. Phys. A, 160, 68-71, 2011.

Khan, R. U., Rahman, Z. U., Nikousefat, Z., Javdani, M., Tufarelli. V., Dario, C., Selvaggi, M., and Laudadio, V.: Immunomodulating effects of vitamin $\mathrm{E}$ in broilers, World. Poultry Sci. J., 68, 31-40, 2012.

O’dea, E. E., Fasenko, G. M., Feddes, J. J. R., Robinson, F. E., Segura, J. C., Ouellette, C. A., and van Middelkoop, J. H.: Investigating the eggshell conductance and embryonic metabolism of modern and unselected domestic avian genetic strains at two flock ages, Poultry Sci., 83, 2059-2070, 2004.

Palozza, P. and Krinsky, N. I.: $\beta$-Carotene and $\alpha$-tocopherol are synergistic antioxidants, Arch. Biochem. Biophys., 297, 184-187, 1992.

Peebles, E. D. and McDaniel, C. D.: A pratical manualfor understanding the shell structure of broiler hatching eggs and measurements of their quality, Bulletin 1139 was published by the Office of Agricultural Communications, May 2004, Mississippi, USA, 1-16, 2004.

Peebles, E. D., Zumwalt, C. D., Doyle, S. M., Gerard, P. D., Latour, M. A., Boyle, C. R., and Smith, T. W.: Effects of breeder age and 
dietary fat source and level on broiler hatching egg characteristics, Poultry Sci., 79, 698-704, 2000.

Possenti, C. D., Karadas, F., Colombo, G., Caprioli, M., Rubolini, D., Milzani, A., Donne, I. D., Saino, N., and Parolini, M.: Antioxidants and embryo phenotype: is there experimental evidence for strong integration of the antioxidant system?, J. Exp. Biol., 220, 615-624, 2017

Salary, J., Sahebi-Ala, F., Kalantar, M., and Matin, H. R. H.: In ovo injection of vitamin $\mathrm{E}$ on post-hatch immunological parameters and broiler chicken performance, Asian Pacific Journal of Tropical Biomedicine, 4, 616-619, 2014

Sas Institute Inc.: SAS for Windows Release, 8, NC, USA, 2007.

Schaal, T. P.: The effect of in ovo feeding of fatty acids and antioxidants on broiler chicken hatchability and chick tissue lipids, The degree of Honors Baccalaureate of Science in Animal Sciences, Oregon State University, Corvallis, USA, 2008.

Seker, I., Kul, A., and Bayraktar, M.: Effects of parental age and hatching egg weight of Japanese quails on hatchability and chick weight, International Journal of Poultry Science, 3, 259-265, 2004

Shafey, T. M.: Effects of egg size and eggshell conductance on hatchability traits of meat and layer breeders flocks, Asian Australasian Journal of Animal Sciences, 15, 1-6, 2002.

Speake, B. K., Surai, P. F., Noble, R. C., Beer, J. V., and Wood, N. A.: Differences in egg lipid and antioxidant composition between wild and captive pheasants and geese, Comp. Biochem. Phys. B, 124, 101-107, 1999.

Surai, P. F.: Tissue-specific changes in the activities of antioxidant enzymes during the development of the chicken embryo, Brit. Poultry Sci., 40, 397-405, 1999.
Surai, P. F.: Natural antioxidants in avian nutrition and reproduction, Nottingham University Press, Nottingham, UK, 2002.

Surai, P. F. and Sparks, N. H. C.: Comparative evaluation of the effect of two maternal diets on fatty acids, vitamin $\mathrm{E}$ and carotenoids in the chick embryo, Brit. Poultry Sci., 42, 252-259, 2001.

Surai, P. F. and Speake, B. K.: Selective excretion of yolk-derived tocotrienols into the bile of the chick embryo, Comp. Biochem. Physiol. B Biochem. Mol. Biol., 121, 393-396, 1998.

Surai, P. F., Noble, R. C., and Speake, B. K.: Tissue-specific differences in antioxidant distribution and susceptibility to lipid peroxidation during development of the chick embryo, BBA-Lipid. Lipid Met., 1304, 1-10, 1996.

Surai, P. F., Speake, B. K., and Sparks, N. H. C.: Carotenoids in avian nutrition and embryonic development. 1. Absorption, availability and levels in plasma and egg yolk, The Journal of Poultry Sci., 38, 1-27, 2001.

Surai, A. P., Surai, P. F., Steinberg, W., Wakeman, W. G., Speake, B. K., and Sparks, N. H.: Effect of canthaxanthin content of the maternal diet on the antioxidant system of the developing chick, Brit. Poultry Sci., 44, 612-619, 2003.

Surai, P. F., Fisinin, V. I., and Karadas, F.: Antioxidant systems in chick embryo development. Part 1. Vitamin E, carotenoids and selenium, Animal Nutrition, 2, 1-11, 2016.

Yang, A., Dunnington, E. A., and Siegel, P. B.: Developmental stability in stocks of White Leghorn chickens, Poultry Sci., 76 , 1632-1636, 1997.

Yannakopoulos, A. L. and Tserveni-Gousi, A. S.: Research note: Effect of breeder quail age and egg weight on chick weight, Poultry Sci., 66, 1558-1560, 1987. 